\title{
Study of Ocean Waves Measured by Collocated HH and VV Polarized X-Band Marine Radars
}

\author{
Zhongbiao Chen, ${ }^{1}$ Yijun He, ${ }^{1}$ and Wankang Yang ${ }^{2}$ \\ ${ }^{1}$ School of Marine Sciences, Jiangsu Engineering Technology Research Center of Marine Environment Detection, \\ Nanjing University of Information Science and Technology, Jiangsu 210044, China \\ ${ }^{2}$ The Second Institute of Oceanography, SOA, Hangzhou 310112, China
}

Correspondence should be addressed to Yijun He; yjhe@nuist.edu.cn

Received 4 April 2016; Revised 2 June 2016; Accepted 16 June 2016

Academic Editor: Björn Lund

Copyright (C) 2016 Zhongbiao Chen et al. This is an open access article distributed under the Creative Commons Attribution License, which permits unrestricted use, distribution, and reproduction in any medium, provided the original work is properly cited.

The significant wave height (SWH) retrieved from collocated HH and VV polarized X-band marine radars under different sea states is studied. The SWH are retrieved from different principal components of X-band marine radar image sequence. As compared with the SWH measured by a buoy, the root-mean-square errors of the SWH are $0.32-0.45 \mathrm{~m}$ for VV polarization, and they are $0.37-$ $0.60 \mathrm{~m}$ for $\mathrm{HH}$ polarization. At the wind speeds of $0-5 \mathrm{~m} / \mathrm{s}$, the SWH can be derived from VV polarized radar images, while the backscatter of $\mathrm{HH}$ polarized radar is too weak to contain wave signals at very low wind speeds $(\sim 0-3 \mathrm{~m} / \mathrm{s})$. At the wind speeds of $5-18 \mathrm{~m} / \mathrm{s}$, the SWH retrieved from VV polarization coincide well with the SWH measured by the buoy, while the SWH retrieved from $\mathrm{HH}$ polarization correspond with the changes of the wind speed. At the wind speeds of $18-26 \mathrm{~m} / \mathrm{s}$, the influence of wave breaking on $\mathrm{HH}$ polarization is more important than that on VV polarization. This indicates that the imaging mechanisms of $\mathrm{HH}$ polarized X-band marine radar are different from those of VV polarized X-band marine radar.

\section{Introduction}

Ocean waves are important to marine activities and scientific studies, such as ocean engineering, coastal environment protection, and upper ocean dynamics. In situ measurements such as buoys have been operationally used to measure ocean waves since the mid-1970s, but they are expensive to deploy and maintenance [1]. In recent years, remote sensing technologies such as satellite altimetry and high-frequency (HF) radar have been used to observe ocean waves [2], but the spatial resolutions of the altimeter and HF radar are about 5-7 km [3] and 0.3-3 km [4], which are not suitable to be used in nearshore area with inhomogeneous wave field. X-band marine radar has high spatial and temporal resolutions, and it has been used in the observation of sea surface wave $[5,6]$, current $[7,8]$, wind $[9,10]$, and bathymetry [11].

Conventional X-band marine radar operates with $\mathrm{HH}$ polarization under low grazing angles. Small wind-induced ripples on the sea surface cause Bragg scattering of the incident wave energy, and this scattering is in turn modulated by the long gravity waves, leading to the "sea clutter" in the radar image [11]. At low grazing angles, non-Bragg scattering also contributes noticeably to the backscatter from sea surface, especially for horizontal polarization [12-15]. In addition, Trizna and Carlson [16] found that there were differences between the spatial texture of $\mathrm{HH}$ polarized radar image and that of VV polarized radar image and attributed them to different scattering mechanisms for $\mathrm{HH}$ and VV polarizations. Cui et al. [17] found that there were differences in the wave and current field retrieved from dual polarized Xband marine radar images, by using a widely used algorithm based on the three-dimensional fast Fourier transform (FFT), which has been shown to be applicable in homogeneous wave field $[5,6]$.

In coastal zones, the wave fields are nonhomogeneous due to the influences of wind, bathymetry, and tide. To inverse nonhomogeneous wave field from $\mathrm{X}$-band marine radar image sequence, new algorithms based on wavelet transform [18] and empirical orthogonal function (EOF) have been proposed $[19,20]$. In the EOF method, the SWH are 


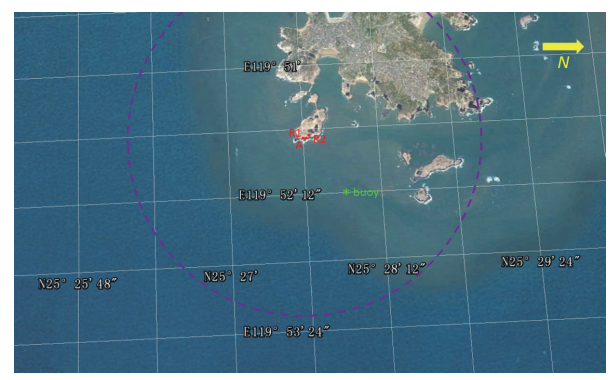

FIgURE 1: Map of the experimental site. The three red dots are the positions of X-band marine radars with $\mathrm{HH}$ and VV polarizations (R1 and R2) and the anemometer (A). The purple dashed circle denotes the observation area of the radars. The green star denotes the location of the buoy. The yellow arrow points to north. The colors of ocean water show the changes of bathymetry.

retrieved from different principal components of X-band marine radar image sequence $[19,20]$. This paper aims to study the differences between $\mathrm{HH}$ and $\mathrm{VV}$ polarized $\mathrm{X}$ band marine radars in the observation of coastal waves. The organization is as follows. The experiment and method are described in Section 2. The SWH inversed from different principal components of $\mathrm{HH}$ and VV polarized X-band marine radars are compared in Section 3. The influences of wind and wave on the imaging of $\mathrm{HH}$ and $\mathrm{VV}$ polarizations are further discussed in Section 4. Finally, the conclusion is given in Section 5.

\section{Experiment and Method}

2.1. Experiment. An experiment was carried out on Haitan Island of China, from December 25, 2014, to January 17, 2015. In the experiment, two X-band marine radars with $\mathrm{HH}$ and VV polarizations, an anemometer, and a pitch-and-roll wave buoy were used to observe the wave field simultaneously. The distances between the $\mathrm{HH}$ and VV polarized X-band marine radars were $10 \mathrm{~m}$ in horizontal and $1 \mathrm{~m}$ in vertical. The two radar systems and the anemometer were set up on the shore that about $15 \mathrm{~m}$ above the sea level and $15-25 \mathrm{~m}$ from the coastline. The wave buoy was moored $1000 \mathrm{~m}$ from the radar stations in the azimuth of $60^{\circ}$, as shown in Figures 1 and 2.

The configurations of the two X-band marine radars are shown in Table 1, and they are the same except the polarization and the antenna rotation speed. The difference between the antenna rotation periods of the two radars is $1.07 \mathrm{~s}$. There were 32 or 64 images in a single radar image sequence, so the time difference between the radars was $34.2 \mathrm{~s}$ or $68.5 \mathrm{~s}$, during which time the changes of the SWH were small. Therefore, the influence of the antenna rotation speeds on the SWH is ignored in this study.

Dedicated $40 \mathrm{MHz}$ analogue to digital converter cards were used to record the radar backscatter from the sea surface and then converted them into gray-level images with a radial resolution of $3.75 \mathrm{~m}$ and an azimuthal resolution of about $0.05^{\circ}$. The measurement ranges of the X-band marine radars were about $3 \mathrm{~km}$, and the fields of view of them were from $0^{\circ}$ to $240^{\circ}$ in azimuth (Figure 1). During the experiment, the $\mathrm{HH}$ and VV polarized radars worked every 7-20 minutes, and
TABLE 1: Configurations of the X-band marine radar systems.

\begin{tabular}{lcc}
\hline Parameters & \multicolumn{2}{c}{ Value } \\
\hline Polarization & $\mathrm{HH}$ & $\mathrm{VV}$ \\
Antenna rotation speed & $42 \mathrm{rot} / \mathrm{min}$ & $24 \mathrm{rot} / \mathrm{min}$ \\
Radar frequency & $9410 \mathrm{MHz} \pm 30 \mathrm{MHz}$ \\
Pulse width & $70 \mathrm{~ns}$ \\
Pulse repetition frequency & $3000 \mathrm{~Hz}$ \\
Transmit power & $25 \mathrm{~kW}$ \\
Gain & $30.2 \mathrm{~dB}$ \\
Beam width & $1.2^{\circ}$ in horizontal, 20.5 in vertical \\
Antenna & $2.4 \mathrm{~m}$ slotted waveguide antenna \\
\hline
\end{tabular}

they operated for 552 hours and 550 hours, respectively. As an example, two collocated radar images recorded by them are shown in Figure 2, where the waves came from east and are refracted toward shore (e.g., the areas in the brown boxes).

The resolutions of the anemometer are $0.1 \mathrm{~m} / \mathrm{s}$ for wind speed and $0.1^{\circ}$ for wind direction. The sampling frequency of the anemometer was $1 \mathrm{~Hz}$, and the wind speeds and directions were averaged every 10 minutes to reduce the influence of local turbulence. There were 559 hours of wind speeds and directions in the experiment, as shown in Figure 3(a). The wind speed varied from $1.3 \mathrm{~m} / \mathrm{s}$ to $25.5 \mathrm{~m} / \mathrm{s}$, and the wind mainly came from northeast.

The buoy used in the experiment was the TRIAXYS ${ }^{\text {TM }}$ mini directional wave buoy (http://axystechnologies.com/ products/triaxys-mini-directional-wave-buoy/). It sampled the sea surface for 20 minutes every hour and then output the wave parameters, including the $\mathrm{SWH}$, the peak wave direction, and the peak wave period. The measurement ranges and accuracies of the SWH are $20 \mathrm{~m}$ and $1 \%$, and those of the peak wave direction are $0-360^{\circ}$ and $3^{\circ}$, respectively. The diameter of the buoy is $0.72 \mathrm{~m}$. Because of the malfunctions of the buoy, there were abnormal values (i.e., $\mathrm{SWH}>10 \mathrm{~m}$ ) and missing values in the observation. After excluding the abnormal values, there were 506 hours of wave parameters. Figure 3(b) shows the SWH and the peak wave direction measured by the buoy. The SWH varied from $0.2 \mathrm{~m}$ to $3.5 \mathrm{~m}$, and the wave directions were mainly from northeast to east.

In addition, the correlation coefficient between the wind speed measured by the anemometer and the SWH measured by the buoy is 0.81 , and Figures 3(a) and 3(b) indicate that the variation of the SWH was similar to that of the wind speed, except the hours when the SWH were less than about $1 \mathrm{~m}$ (i.e., the hours of 83-157 and 230-280); although there were deviations between the directions of wind and wave, the influence of wind on wave was important in the observation area.

2.2. Method. In this study, the SWH is retrieved from X-band marine radar image sequence by using the method based on EOF analysis [19]. X-band marine radar image sequence is firstly decomposed into different principal components, and then the SWH is estimated by a linear relationship:

$$
\mathrm{SWH}=A \cdot \operatorname{std}\left(z_{i}\right)+B,
$$

where $z_{i}(i=1,2, \ldots, n)$ is one principal component, $\operatorname{std}(\cdot)$ is the standard deviation, $n$ is the number of principal 

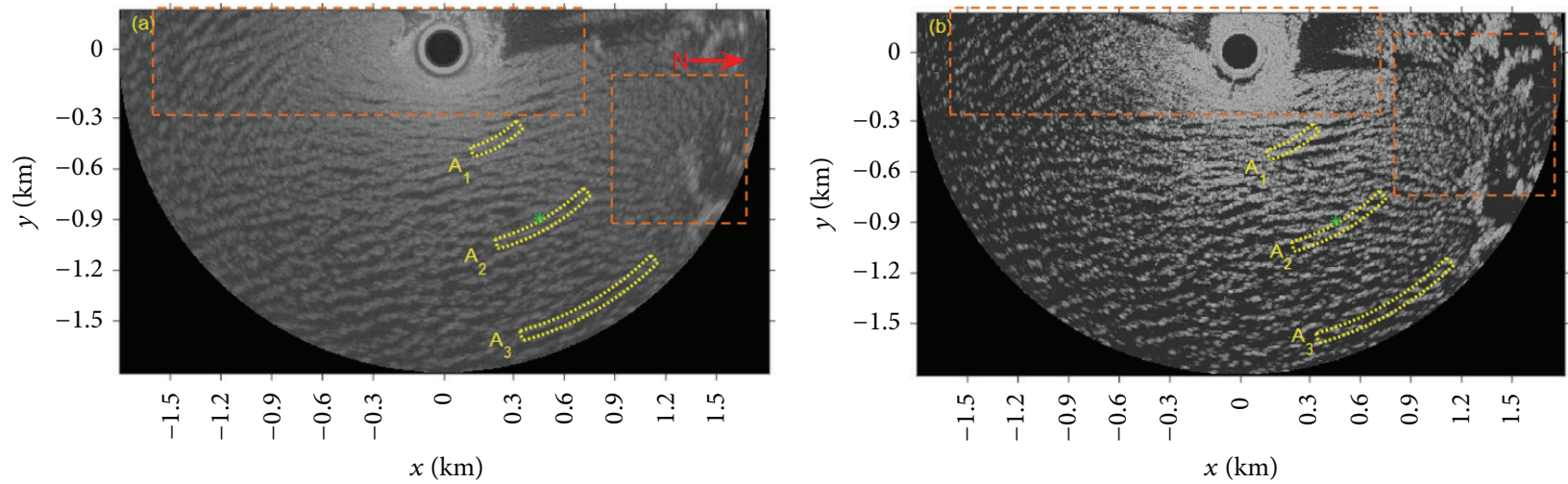

FIgURE 2: Two X-band marine radar images captured at 12:15 on December 27, 2014, by (a) VV polarized radar and (b) HH polarized radar. The red arrow points to the north direction. The yellow bins A1, A2, and A3 are the study regions. The green stars denote the location of the buoy. The brown boxes show the refraction of waves.

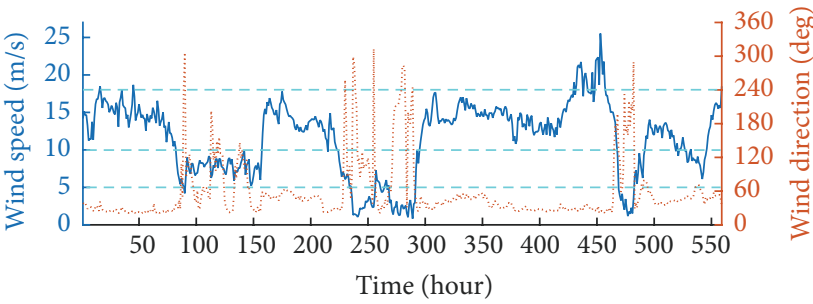

(a)

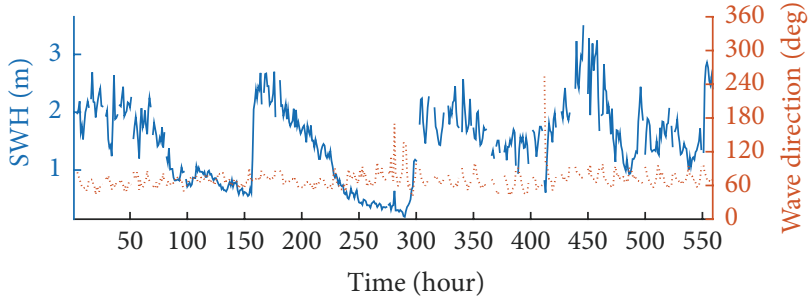

(b)

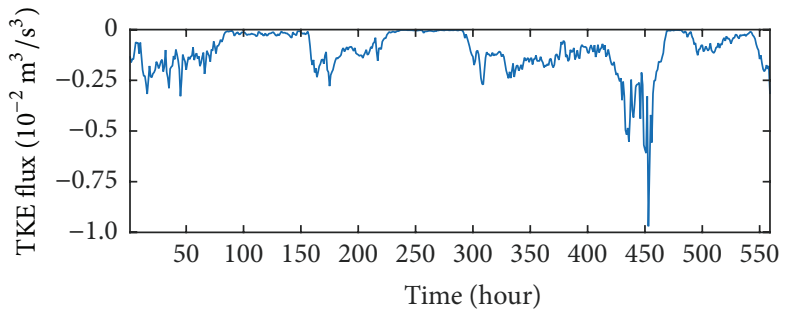

(c)

FIGURE 3: (a) The wind speed and wind direction measured by the anemometer, (b) the SWH and peak wave direction measured by the buoy, and (c) the TKE flux through the sea surface due to whitecapping. The cyan dashed lines in (a) denote the wind speeds of $5 \mathrm{~m} / \mathrm{s}, 10 \mathrm{~m} / \mathrm{s}$, and $18 \mathrm{~m} / \mathrm{s}$.

components, and $A$ and $B$ are two coefficients that need to be calibrated by in situ measurements of the buoy. To compare with the SWH measured by the buoy, the SWH retrieved from $\mathrm{X}$-band marine radar image sequences during the working time of the buoy are averaged every hour.

The coefficients $A$ and $B$ (Equation (1)) are calibrated as follows. First, the SWH measured by the buoy are divided into several groups with an interval of $0.5 \mathrm{~m}$. Second, half of the SWH are randomly selected from each group to get the training dataset, while the other half of the SWH are used as the test dataset. Third, the training dataset and the SWH retrieved from simultaneous $\mathrm{X}$-band marine radar image sequences are fitted to determine the coefficients, and the test dataset is used to evaluate the fitting.

To study the difference between the SWH retrieved from $\mathrm{HH}$ and VV polarized X-band marine radars, three study regions are selected, as shown in Figure 2. The azimuths of Regions $\mathrm{A} 1, \mathrm{~A} 2$, and $\mathrm{A} 3$ are $135-165^{\circ}$, and the ranges of them are $450.0-510.0 \mathrm{~m}, 1012.5-1072.5 \mathrm{~m}$, and 1575.0 $1635.0 \mathrm{~m}$, respectively. Because there was only one buoy near Region A2, the SWH of Regions A1-A3 are all calibrated by using the buoy, although the SWH in different regions may be different. This may be reasonable for Region A3, but there may be large error for Region A1, because the water depths of Regions A2 and A3 were close (i.e., 25-30 m) while that of Region A1 was about 10-15 m.

Moreover, whitecapping often occurred on the sea surface, especially under high sea states. To study the influence of wave breaking on $\mathrm{HH}$ and VV polarizations, the turbulent kinematic energy (TKE) flux through the sea surface due to whitecap is estimated from the wind speeds by the model [21], as shown in Figure 3(c). The absolute values of the TKE fluxes at low wind speeds were smaller than those at moderate and high wind speeds, which indicate that whitecapping was 


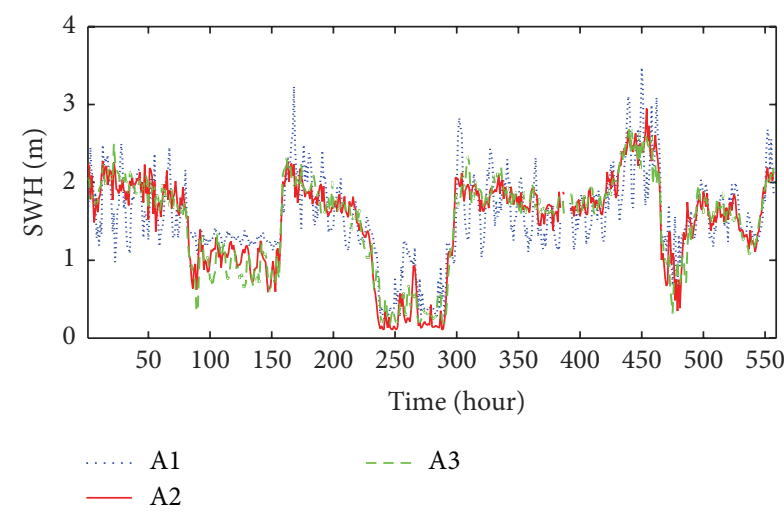

(a) $\mathrm{HH}$

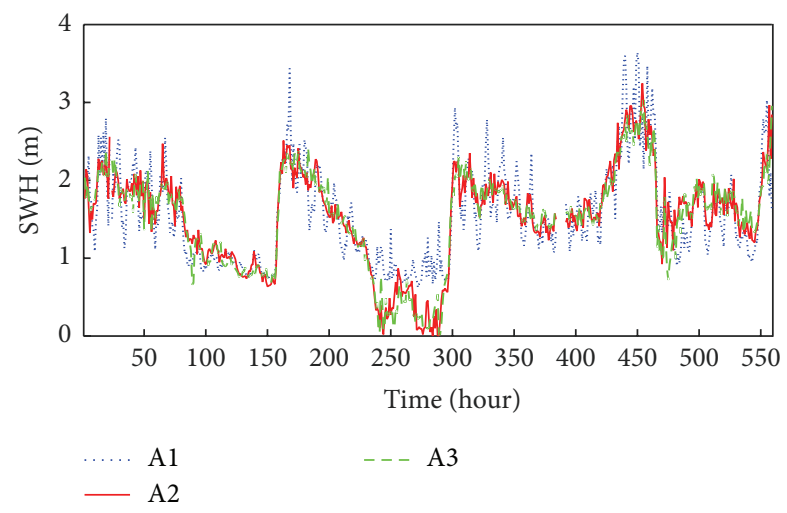

(b) VV

FIGURE 4: The SWH retrieved from the first principal component of X-band marine radars in Regions A1-A3. (a) HH polarization and (b) VV polarization.

TABLE 2: The calibration coefficients for the first principal component of $\mathrm{HH}$ and VV polarized X-band marine radars in Regions A1A3.

\begin{tabular}{lcccc}
\hline & $A(\mathrm{HH})$ & $B(\mathrm{HH})$ & $A(\mathrm{VV})$ & $B(\mathrm{VV})$ \\
\hline Region A1 & 0.0024 & 0.0470 & 0.0061 & 0.0697 \\
Region A2 & 0.0020 & -0.0604 & 0.0062 & -0.2835 \\
Region A3 & 0.0027 & -0.0247 & 0.0078 & -0.3000 \\
\hline
\end{tabular}

active in this region under moderate and high sea states. It is noted that the model [21] is a parameterization of whitecapping, and the TKE flux is used here as a reference for the activeness of wave breaking, while the exact locations or areas of whitecapping cannot be obtained.

\section{Result and Discussion}

In this section, the SWH are retrieved from $\mathrm{HH}$ and $\mathrm{VV}$ polarized X-band marine radars and then compared with the SWH measured by the buoy and the wind speed measured by the anemometer. The spectra of different principal components are also analyzed.

3.1. Validation of the SWH. To retrieve the SWH from Xband marine radar image sequences by (1), the coefficients $A$ and $B$ are firstly calibrated. Take the first principal component as an example, the calibration coefficients for $\mathrm{HH}$ and $\mathrm{VV}$ polarizations are shown in Table 2, and the inversed SWH are shown in Figure 4. Although the SWH retrieved from Xband marine radar image sequences of different polarizations are close, there are some differences between them. For example, in the hours of $83-157$, the SWH retrieved from $\mathrm{HH}$ polarization decreased suddenly and then fluctuated periodically (Figure 4(a)), while the SWH retrieved from VV polarization decreased gradually (Figure 4(b)). For both $\mathrm{HH}$ and VV polarizations, the SWH in Region A2 is close to that in Region A3, while the SWH in Region A1 shows an apparent period of about 12 hours. Because the semidiurnal tide is the major tidal constituent in the observation area [22], the influence of tide on the SWH in Region Al was important [23].

To evaluate the SWH retrieved from X-band marine radar image sequences, they are compared with the measurements of the buoy and the anemometer, as shown in Figure 5.

The root-mean-square error (RMSE) between the SWH measured by the buoy and those retrieved from different polarized radars is shown in Figure 5(a). The RMSE of the SWH retrieved from VV polarization are $0.32-0.45 \mathrm{~m}$ in Regions A1-A3, which are smaller than those retrieved from $\mathrm{HH}$ polarization (i.e., 0.37-0.60 m), except the 1-3 principal components in Region A1. For VV polarization, the RMSE in Regions A2 and A3 are close, which are larger than the RMSE in Region Al; for $\mathrm{HH}$ polarization, the RMSE increase from Region A3 to Region A1.

The correlation coefficients between the wind speed and the SWH retrieved from X-band marine radars are shown in Figure 5(b). For both $\mathrm{HH}$ and $\mathrm{VV}$ polarizations, the correlation coefficients decrease from offshore (Region A3) to nearshore (Region A1), because the influence of tide on waves increases as the waves propagate toward shore. There are differences between $\mathrm{HH}$ and VV polarizations. First, the changes of the correlation coefficients of $\mathrm{VV}$ polarization (i.e., 0.75-0.90) are smaller than those of $\mathrm{HH}$ polarization (i.e., 0.52-0.95) in Regions A1-A3. Second, the correlation coefficients maximize at the 1-2nd principal component for $\mathrm{HH}$ polarization, while they maximize at the 3-4th principal component for VV polarization. Therefore, the influences of wind on $\mathrm{HH}$ polarization are different from that on $\mathrm{VV}$ polarization, which coincides with previous studies [16].

3.2. Comparison with the SWH Measured by the Buoy. To study the differences between $\mathrm{HH}$ and $\mathrm{VV}$ polarizations under different sea states, the observations are divided into four sea states according to the wind speeds. Because the sea states change a little in a short time period, continuous observations are divided into the same dataset as far as possible (Figure 3(a)), as shown in Table 3.

The RMSE between the SWH measured by the buoy and those retrieved from different principal components of $\mathrm{HH}$ 


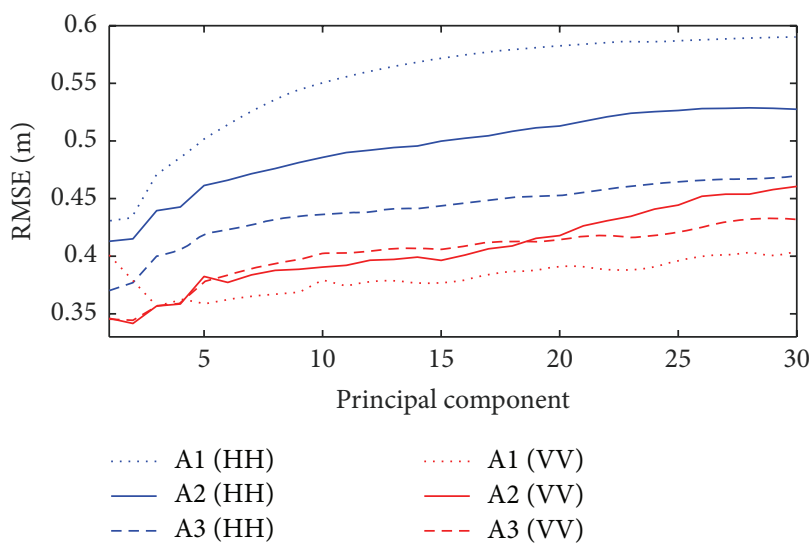

(a)

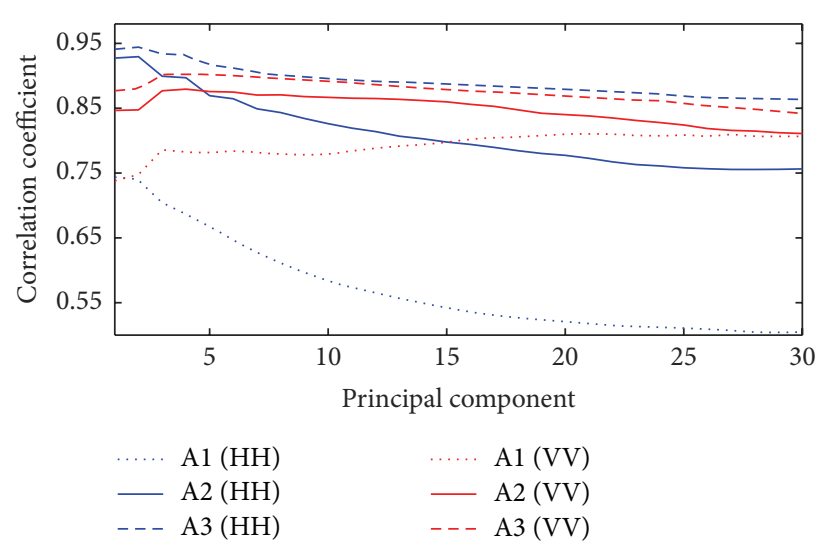

(b)

FIGURE 5: (a) The RMSE between the SWH measured by the buoy and those retrieved from different principal components of X-band marine radars, and (b) the correlation coefficients between the wind speed and the SWH retrieved from different principal components of X-band marine radars in Regions A1-A3.

TABLE 3: Division of the sea states.

\begin{tabular}{lccc}
\hline Number & Sea states & Wind speed $(\mathrm{m} / \mathrm{s})$ & $\begin{array}{c}\text { Time period } \\
\text { (hour) }\end{array}$ \\
\hline 1 & Low & $0 \leq u<5$ & $235-291$, \\
$469-482$ \\
2 & Low to moderate & $5 \leq u<10$ & $83-157$ \\
& & $1-82$, \\
& & & $158-222$, \\
& Moderate to high & $10 \leq u<18$ & $296-429$, \\
& & & $458-467$, \\
4 & & $18 \leq u<26$ & $492-520$ \\
4 & High & & $429-458$ \\
\hline
\end{tabular}

and VV polarized X-band marine radar image sequences are shown in Figure 6.

At the wind speeds of $0-5 \mathrm{~m} / \mathrm{s}$ (Figure 6(a)), the RMSE of the 1-5th principal component of $\mathrm{VV}$ polarization are smaller than those of $\mathrm{HH}$ polarization in Regions A1-A3. The RMSE of the 6-30th principal component change irregularly, because the backscatter from sea surface is weak, and there is little information on ocean wave in these principal components.

At the wind speeds of $5-26 \mathrm{~m} / \mathrm{s}$ (Figures 6(b) $-6(\mathrm{~d})$ ), the variations of RMSE with the principal components are the same as that in Figure 5(a), but the RMSE are different for different sea states. The RMSE at the wind speeds of 10$18 \mathrm{~m} / \mathrm{s}$ (Figure $6(\mathrm{c})$ ) are smallest, that is, $0.27-0.37 \mathrm{~m}$ for VV polarization and $0.32-0.48 \mathrm{~m}$ for $\mathrm{HH}$ polarization. The RMSE at the wind speeds of $18-26 \mathrm{~m} / \mathrm{s}$ (Figure $6(\mathrm{~d})$ ) are largest, that is, $0.42-0.82 \mathrm{~m}$ for $\mathrm{VV}$ polarization and $0.50-1.28 \mathrm{~m}$ for $\mathrm{HH}$ polarization. Because the whitecap was energetic at high wind speeds (Figure 3(c)), which have more important influence on $\mathrm{HH}$ polarization than on VV polarization [24], the large errors at high wind speeds are possibly caused by breaking waves.
TABLE 4: The correlation coefficients between the SWH measured by the buoy and those retrieved from first principal components of $\mathrm{HH}$ and VV polarized radars, and the correlation coefficients between the wind speeds and the retrieved SWH in Region A2 under different sea states.

\begin{tabular}{lcc}
\hline & $\begin{array}{c}\text { SWH } \\
\text { measured by } \\
\text { the buoy }\end{array}$ & Wind speed \\
\hline SWH of HH (sea state 2) & 0.27 & 0.63 \\
SWH of VV (sea state 2) & 0.73 & 0.27 \\
SWH of HH (sea state 3) & 0.51 & 0.67 \\
SWH of VV (sea state 3) & 0.66 & 0.52 \\
\hline
\end{tabular}

Moreover, Table 4 lists the correlation coefficients between the SWH retrieved from the first principal component and the SWH measured by the buoy in Region $\mathrm{A} 2$ and the correlation coefficients between the retrieved $\mathrm{SWH}$ and the wind speeds. It shows that the SWH retrieved from $\mathrm{HH}$ polarized radar coincide better with the wind speed, while the SWH retrieved from VV polarized radar coincide better with the SWH measured by the buoy under sea states 2 and 3 (i.e., at the wind speeds of $5-18 \mathrm{~m} / \mathrm{s}$ ). Take the SWH in sea state 2 as an example. As shown in Figure 4, the $\mathrm{SWH}$ retrieved from $\mathrm{HH}$ polarization decreased suddenly in the hours of 83-157, which coincides well with the variation of the wind speed (Figure 3(a)); the SWH retrieved from VV polarization decreased gradually in the hours of $83-157$, which is the same as the variation of the SWH measured by the buoy. Because the wave buoy measures only the waves with wavelengths greater than the diameter of the buoy (i.e., $>0.72 \mathrm{~m}$ here) [25], while ripples or capillary waves are mainly caused by winds [26], long gravity waves are important to the imaging of $\mathrm{VV}$ polarization while ripples or capillary waves are more important to the imaging of $\mathrm{HH}$ polarized $\mathrm{X}$-band marine radar. 

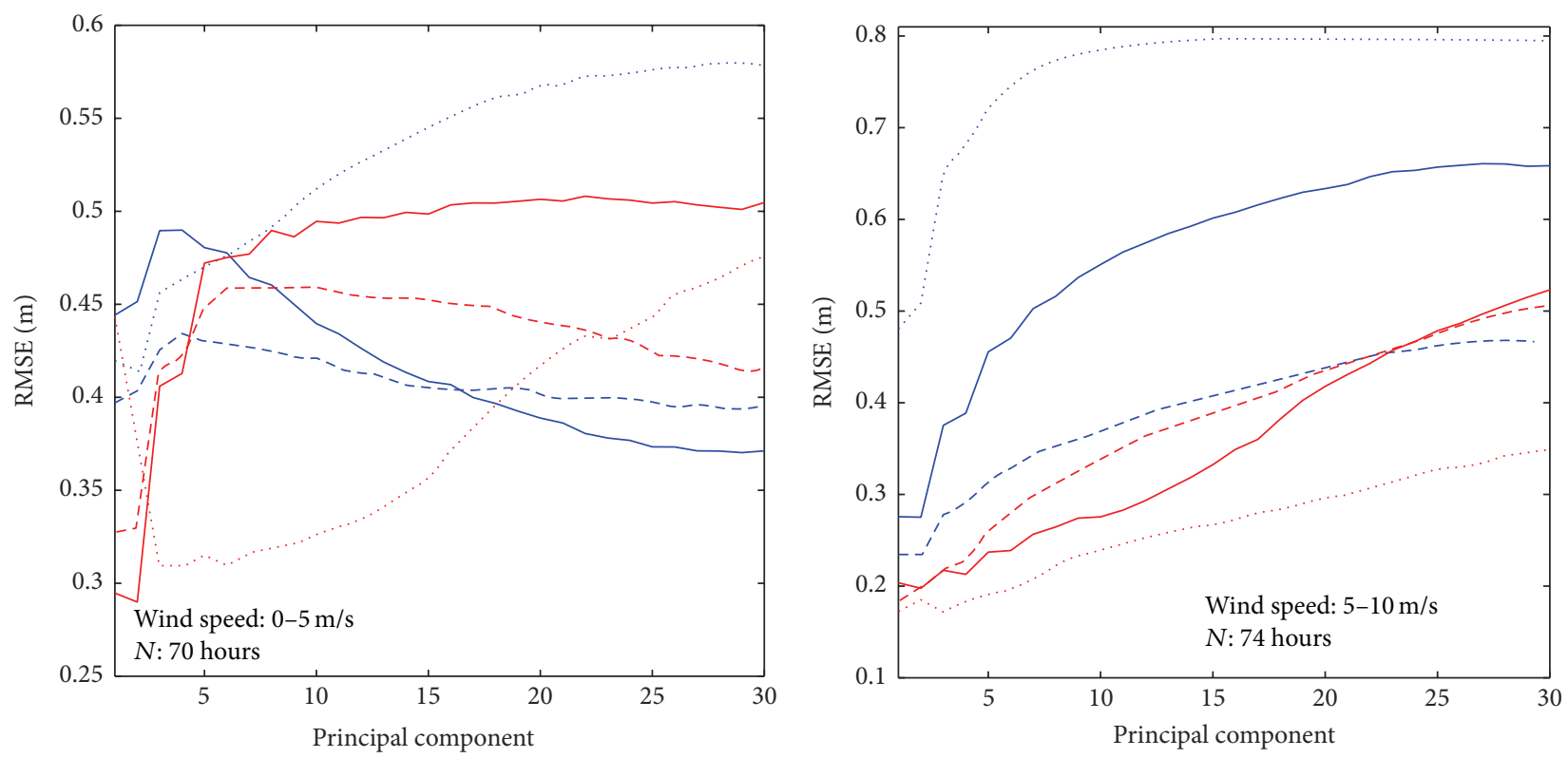

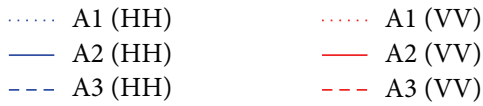

(a)

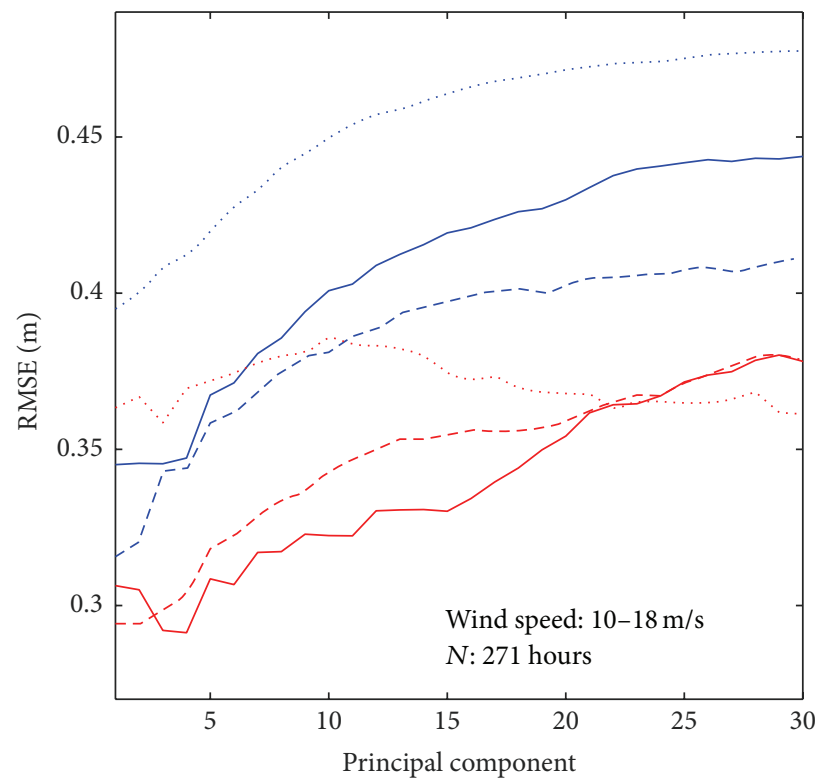

$\begin{array}{ll}\ldots . . . & \mathrm{A} 1(\mathrm{HH}) \\ - & \mathrm{A} 2(\mathrm{HH}) \\ \ldots & \mathrm{A} 3(\mathrm{HH})\end{array}$

$\mathrm{A} 1(\mathrm{VV})$

$-\mathrm{A} 2(\mathrm{VV})$

$---\mathrm{A} 3(\mathrm{VV})$

(c)

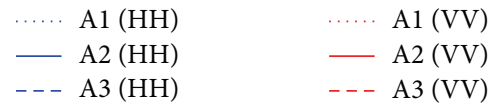

(b)
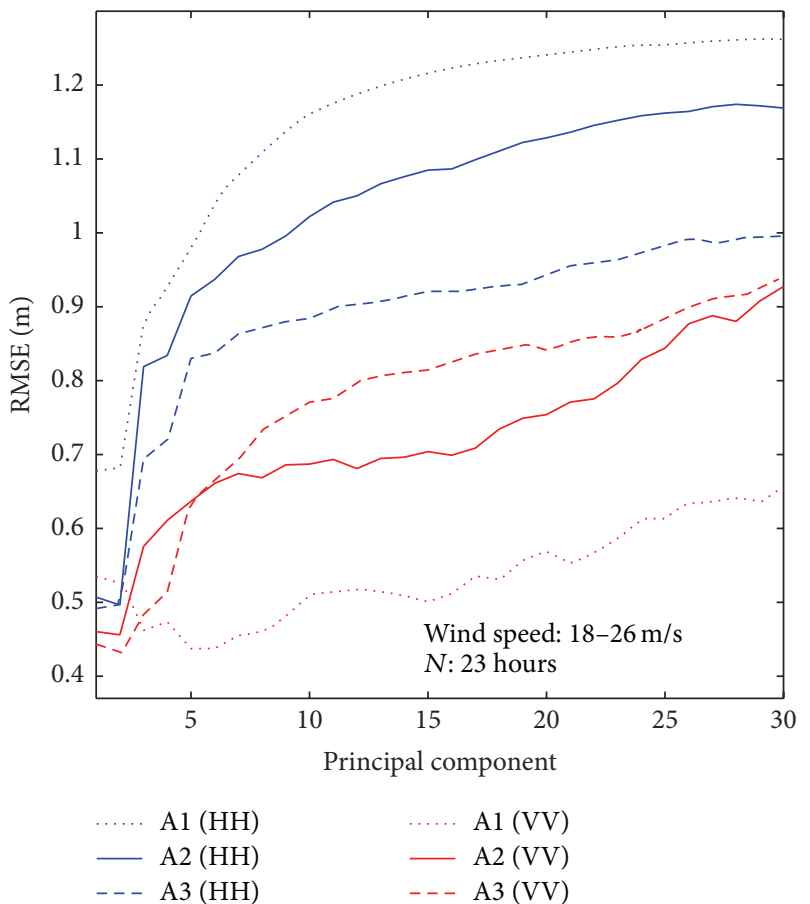

(d)

FIGURE 6: The RMSE between the SWH measured by the buoy and those retrieved from different principal components of X-band marine radars, at the wind speeds of (a) $0-5 \mathrm{~m} / \mathrm{s}$, (b) $5-10 \mathrm{~m} / \mathrm{s}$, (c) $10-18 \mathrm{~m} / \mathrm{s}$, and (d) $18-26 \mathrm{~m} / \mathrm{s}$. The number " $N$ " at the bottom of each panel denotes the number of hours used in the statistics.

3.3. Comparison with the Wind Speed. To study the influence of wind on $\mathrm{HH}$ and $\mathrm{VV}$ polarizations, the correlation coefficients between the wind speed and the SWH retrieved from X-band marine radars are shown in Figure 7. It indicates that the relationship between the SWH and the wind speed is very different for $\mathrm{HH}$ and VV polarizations. 

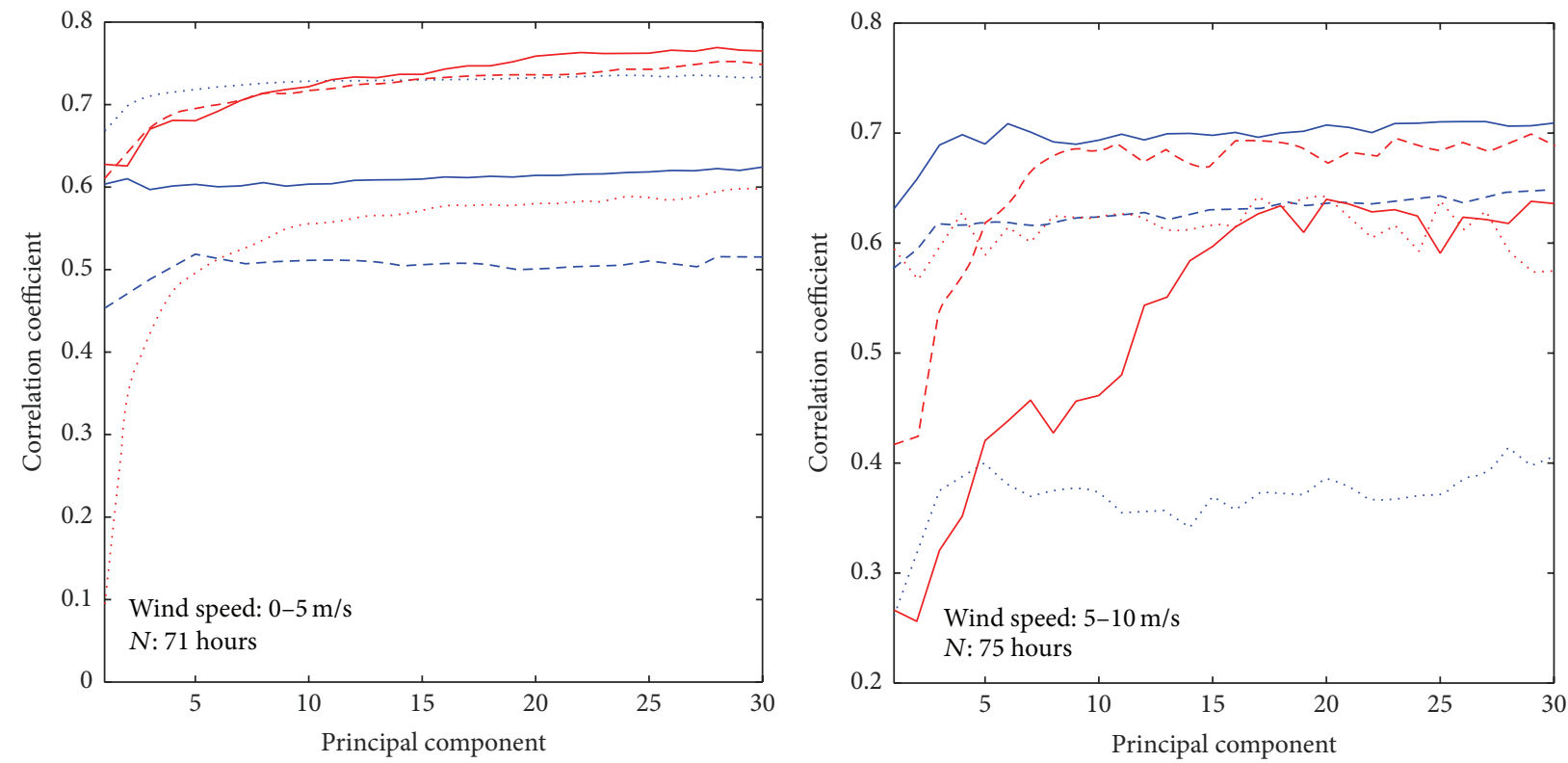

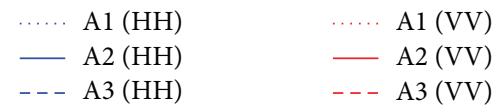

(a)

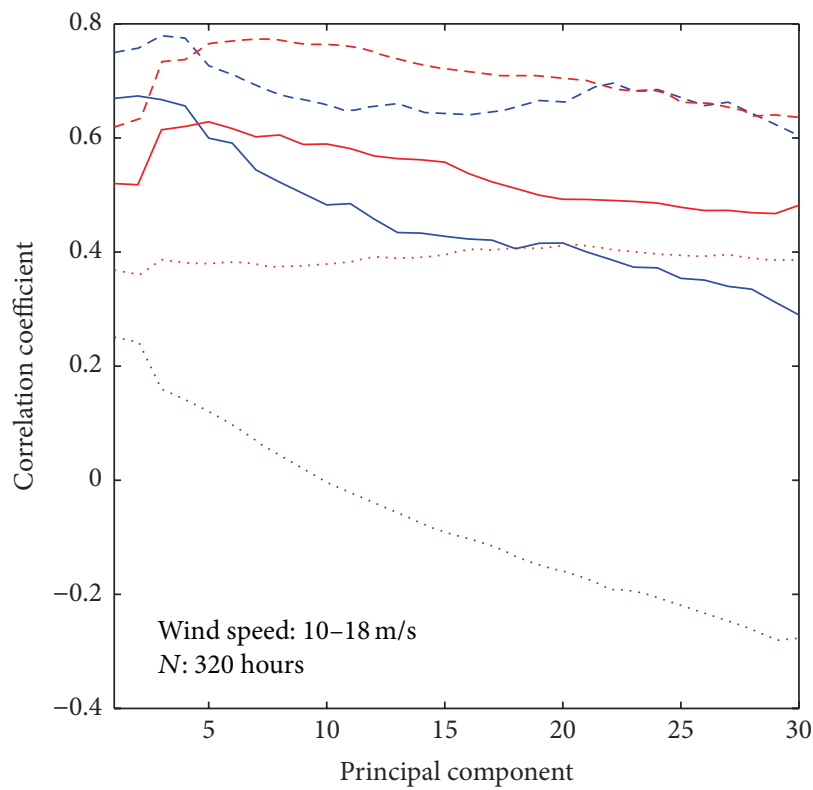

\begin{tabular}{|c|c|}
\hline$\ldots \ldots$ Al $(\mathrm{HH})$ & $\ldots \ldots$ A $1(\mathrm{VV})$ \\
\hline$-\mathrm{A} 2(\mathrm{HH})$ & $\longrightarrow \mathrm{A} 2(\mathrm{VV})$ \\
\hline$---\mathrm{A} 3(\mathrm{HH})$ & $---\mathrm{A} 3(\mathrm{VV})$ \\
\hline
\end{tabular}

(c)

\begin{tabular}{|c|c|}
\hline $\mathrm{A} 1(\mathrm{HH})$ & ..... A1 (VV) \\
\hline$-\mathrm{A} 2(\mathrm{HH})$ & $-\mathrm{A} 2(\mathrm{VV})$ \\
\hline$---\mathrm{A} 3(\mathrm{HH})$ & $---\mathrm{A} 3(\mathrm{VV})$ \\
\hline
\end{tabular}

(b)

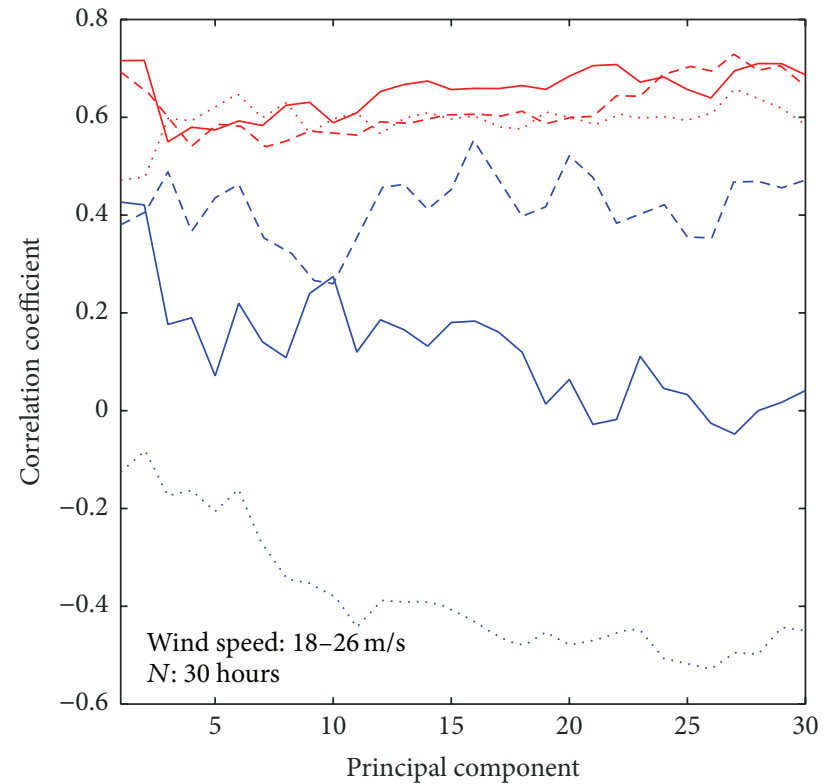

$-\mathrm{A} 2(\mathrm{HH})$

- - A3 $(\mathrm{HH})$

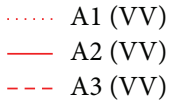

(d)

FIGURE 7: The correlation coefficients between the wind speed and the SWH retrieved from different principal components of HH and VV polarized X-band marine radars, at the wind speeds of (a) $0-5 \mathrm{~m} / \mathrm{s}$, (b) $5-10 \mathrm{~m} / \mathrm{s}$, (c) $10-18 \mathrm{~m} / \mathrm{s}$, and (d) $18-26 \mathrm{~m} / \mathrm{s}$. The number " $N$ " at the bottom of each panel denotes the number of hours used in the statistics. 
For $\mathrm{HH}$ polarization, one has the following:

(i) At low wind speed (Figure 7(a)), the correlation coefficients between the SWH in Region A1 and the wind speed are largest, and they decrease from nearshore (Region A1) to offshore (Region A3). This is because the backscatter from sea surface is too weak to contain wave signal at low wind speeds [27], and it also attenuates with the ranges from the radar station.

(ii) At the wind speeds of $5-10 \mathrm{~m} / \mathrm{s}$ (Figure $7(\mathrm{~b})$ ), the correlation coefficients in Regions A2 are larger than those in Regions A3 and A1; at the wind speeds of $10-26 \mathrm{~m} / \mathrm{s}$ (Figures $7(\mathrm{c})$ and $7(\mathrm{~d})$ ), the correlation coefficients are largest in Region A3 and decrease from offshore (Region A3) to nearshore (Region A1). This is because the backscatter from sea surface increases as the wind speed increases.

(iii) Comparing Figures 7 (c) with $7(\mathrm{~d})$, the correlation coefficients under moderate sea states are larger than those under high sea states. Because wave breaking becomes important at high wind speeds (Figure 3(c)), this may also indicate that $\mathrm{HH}$ polarization is greatly affected by wave breaking.

For VV polarization, one has the following:

(i) At low wind speed (Figure 7(a)), the correlation coefficients in Regions A2 and A3 are larger than those in Region A1. This indicates that the backscatter from sea surface in offshore regions (Regions A2 and A3) contains wave signals at low wind speed, and the small correlation coefficients in Region A1 are caused by the tide (Figure 4(b)) or the saturation of backscatter in this region.

(ii) At the wind speeds of $5-10 \mathrm{~m} / \mathrm{s}$ (Figure $7(\mathrm{~b})$ ), the correlation coefficients of the first several principal components (i.e., $1-15$ in Region A2 and 1-8 in Region A3) are small. This further indicates that VV polarization is insensitive to rapid changes of the wind speed, and thus the influence of long gravity waves may be more important than that of capillary waves on VV polarization.

(iii) Comparing Figures $7(\mathrm{c})$ with $7(\mathrm{~d})$, the correlation coefficients of Regions A2 and A3 change a little from moderate sea state to high sea state, so the influence of wave breaking on VV polarization is small. The correlation coefficients in Region A1 increase with increasing wind speeds, which indicate the influence of wind is more important than that of tide on waves.

3.4. Wave Spectra of Different Principal Components. The SWH are retrieved from different principal components of $\mathrm{HH}$ and VV polarized X-band marine radar image sequences, so the normalized wavenumber spectra of different principal components are studied. The spectrum is calculated as follows. First, decompose one X-band marine radar image sequence into different principal components [19]; second, choose one of the principal components and reconstruct a new image; third, the two-dimensional wavenumber spectrum of the selected principal component is obtained by twodimensional Fourier transform of the reconstructed image, and the directional ambiguity of the spectrum is eliminated according to the wave direction; finally, the one-dimensional wavenumber spectrum is derived by integrating the twodimensional spectrum and then normalized by dividing the maximum of the spectrum.

The wavenumber spectra of different principal components at four typical wind speeds are shown in Figure 8. The four wind speeds are chosen from four sea states, which occurred in the hours of $237,93,52$, and 453 , respectively (Figure $3(\mathrm{a})$ ). The study region is selected to be $135-165^{\circ}$ in azimuthal direction and $520-1480 \mathrm{~m}$ in radial direction, which is centered on the location of the buoy. The $2 \mathrm{nd}, 7 \mathrm{th}$, 12 th, and 20th principal components are selected as examples. The black dashed lines show the peak wavenumbers measured by the buoy, which are close to the peak wavenumbers of the 2nd principal components (the red dotted lines) except those under low sea states [19]. The peak wavenumber measured by the buoy does not coincide exactly with the spectral peaks of the original radar images (the blue lines), because a modulation transfer function is needed to convert the spectra of radar images into the spectra of ocean waves [28], which is not taken into consideration here.

Figures $8(\mathrm{a})$ and $8(\mathrm{~b})$ show the wavenumber spectra at the wind speed of $1.3 \mathrm{~m} / \mathrm{s}$. The spectra of the original VV and $\mathrm{HH}$ polarized radar images (the blue lines) are very different, and there are three peaks in Figure 8(a) at the wavenumbers of $0.014 \mathrm{rad} / \mathrm{m}, 0.056 \mathrm{rad} / \mathrm{m}$ and $0.097 \mathrm{rad} / \mathrm{m}$, while there are many small peaks in Figure 8(b). The peak ocean wavenumber can be estimated from the peak wavenumbers of $\mathrm{VV}$ polarization, while the peak ocean wavenumber is contaminated in the spectrum of $\mathrm{HH}$ polarization. This indicates that $\mathrm{VV}$ polarization is less affected than $\mathrm{HH}$ polarization by low sea state.

At the wind speeds of $8.0 \mathrm{~m} / \mathrm{s}, 14.3 \mathrm{~m} / \mathrm{s}$, and $25.5 \mathrm{~m} / \mathrm{s}$ (Figures $8(\mathrm{c})-8(\mathrm{~h})$ ), the spectral peaks of the original images are the same for $\mathrm{HH}$ and VV polarizations (i.e., $0.076 \mathrm{rad} / \mathrm{m}$, $0.069 \mathrm{rad} / \mathrm{m}$, and $0.055 \mathrm{rad} / \mathrm{m}$, resp.), so the peak wave signals were acquired by both polarizations.

There is one peak in the spectrum of the 2 nd or 7 th principal component, which is close to the peak frequency of ocean wave, because the first several principal components (usually named main principal components in EOF analysis) account for most of the information of ocean waves [19]. The red and green lines in Figure 8 show that the peak wavenumbers of the main principal components of VV polarization are usually smaller than those of $\mathrm{HH}$ polarization; for example, at the wind speed of $14.3 \mathrm{~m} / \mathrm{s}$, the peak wavenumbers of the 2 nd principal component are $0.069 \mathrm{rad} / \mathrm{m}$ and $0.076 \mathrm{rad} / \mathrm{m}$ for $\mathrm{VV}$ and $\mathrm{HH}$ polarizations (Figures 8(e) and 8(f)); at the wind speeds of $14.3 \mathrm{~m} / \mathrm{s}$ and $25.5 \mathrm{~m} / \mathrm{s}$ (Figures $8(\mathrm{e})-8(\mathrm{~h})$ ), the peak wavenumbers of the 7 th principal component are $0.900 \mathrm{rad} / \mathrm{m}$ and $0.055 \mathrm{rad} / \mathrm{m}$ for VV polarization, while they are $0.110 \mathrm{rad} / \mathrm{m}$ and $0.083 \mathrm{rad} / \mathrm{m}$ for $\mathrm{HH}$ polarization, respectively. Because the spectral peaks of the main principal components are possibly caused by the ocean waves with different wavelengths [19], this also 

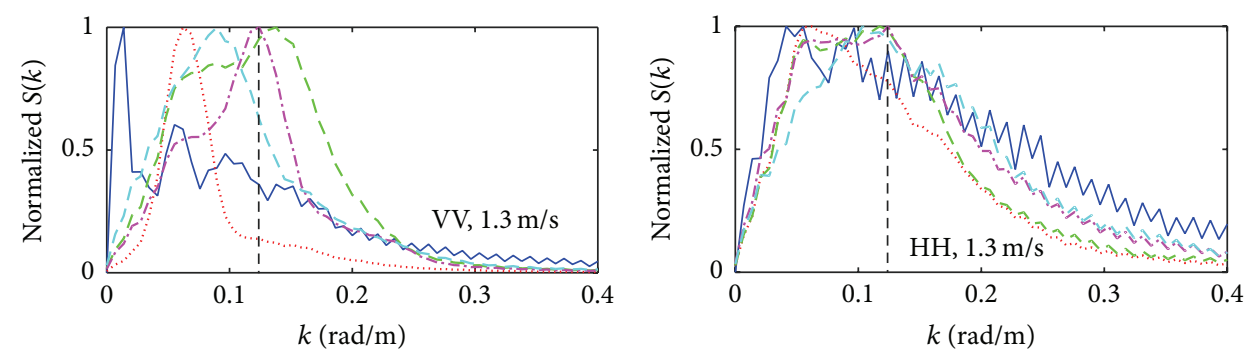

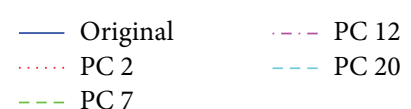

(a)

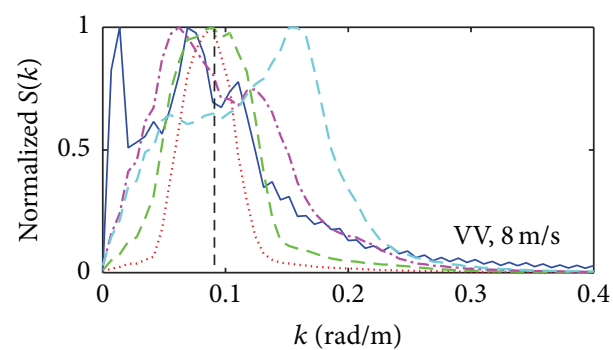

(c)

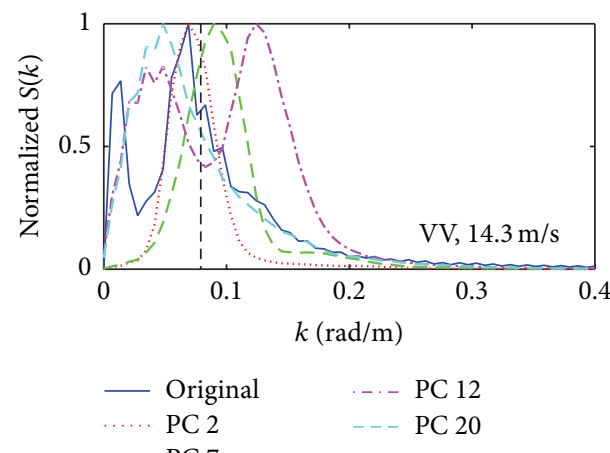

(e)

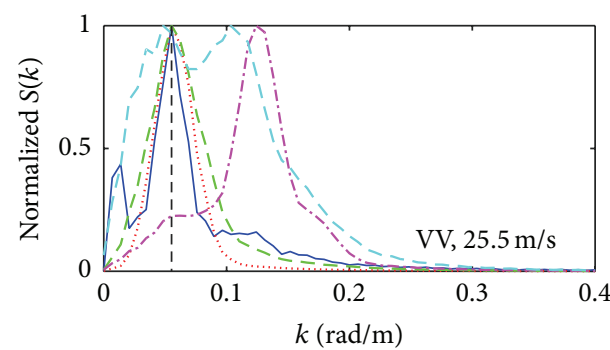

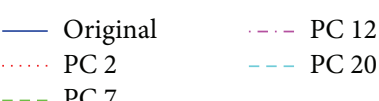

(b)
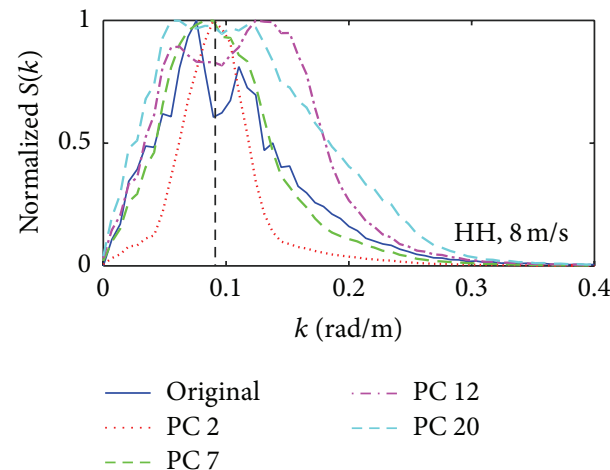

(d)
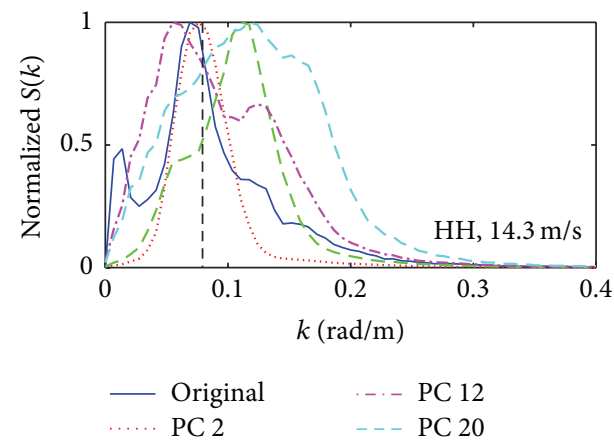

$---\mathrm{PC} 7$

(f)

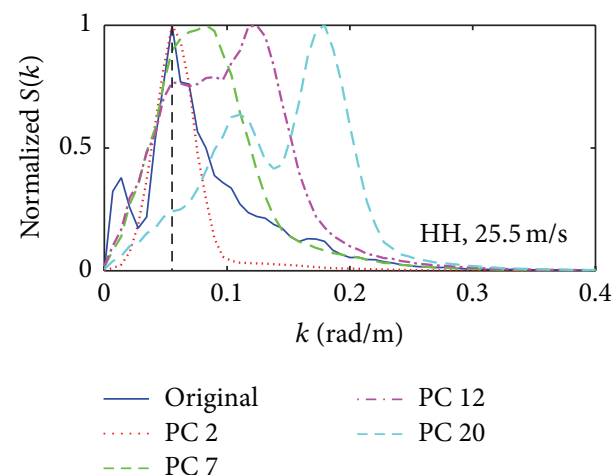

(h)

(g)

FIGURE 8: The normalized wavenumber spectra of different principal components of $\mathrm{HH}$ and VV polarized X-band marine radars, at the wind speeds of ((a) and (b)) $1.3 \mathrm{~m} / \mathrm{s},((\mathrm{c})$ and $(\mathrm{d})) 8.0 \mathrm{~m} / \mathrm{s}$, ((e) and (f)) $14.3 \mathrm{~m} / \mathrm{s}$, and $((\mathrm{g})$ and (h)) $25.5 \mathrm{~m} / \mathrm{s}$. The vertical black dashed lines denote the peak wavenumbers measured by the buoy. 
indicates that $\mathrm{VV}$ polarization is mainly affected by long waves while $\mathrm{HH}$ polarization is affected by short waves.

There are two or more peaks in the spectrum of the 12th or 20th principal component. Because the spectral densities of these principal components are much smaller than the spectral densities of the original radar images (the blue lines in Figure 8), they are easily contaminated by random noises from the wave field and the radar systems. Therefore, there are large differences in these principal components between $\mathrm{HH}$ and VV polarizations.

In addition, the peak at $0.014 \mathrm{rad} / \mathrm{m}$ occurs in the spectra of VV polarization under different sea states (Figures 8(a), $8(\mathrm{c}), 8(\mathrm{e})$, and $8(\mathrm{~g}))$, which is most significant at low wind speed, and weakens as the wind speed increases (the changes of the peaks are in a relative sense because normalized spectra are used). It also occurs in the spectra of $\mathrm{HH}$ polarization under moderate and high sea states (Figures 8(f) and 8(h)). Therefore, the peak may be caused by the background noise of radar system, long gravity waves, or non-Bragg scattering mechanisms, but more observations are needed to determine the reasons.

\section{Discussion}

There are differences between the SWH inversed from $\mathrm{HH}$ and VV polarized $\mathrm{X}$-band marine radars, which indicate that the imaging mechanisms of $\mathrm{HH}$ and $\mathrm{VV}$ polarizations are different. The influences of wind and wave on different polarizations are further analyzed.

During low wind speeds, there is usually some residual energy (e.g., swell) on lower frequencies that might even be of the same order as the high-frequency part, which follows a $f^{-4}$ wind dependent power law [29, 30]. Moreover, the low-frequency part is well resolved by the wave buoy, while the high-frequency part is not (the measurement range of frequency was $0.03-0.67 \mathrm{~Hz}$ for the buoy in the experiment). For $\mathrm{HH}$ polarization, the inversed $\mathrm{SWH}$ have a low correlation with the SWH measured by the buoy but a high correlation with the wind speeds (Figures 6 and 7 and Table 4), so the $\mathrm{HH}$ polarized radar mainly measures the higher frequencies of ocean wave. For VV polarization, the inversed SWH correlates with these lower frequency SWH measured by the wave buoy, while they get little information about the wind speed since there is no longer wave under the influence of the wind, so the VV polarized radar mainly measures the lower frequencies of ocean wave.

During high wind speeds, the waves that are under the direct influence of the wind will grow to even the lower frequencies. This means than any "residual" lower frequency energy is dominated by the wind driven waves. Since these waves follow the wind dependent $f^{-4}$ power law $[29,30]$, even the lower frequency waves will now contain information about the wind. For $\mathrm{HH}$ polarization, correlation with the wind speed will still be high, since the high-frequency part still follows the wind speed dependent $f^{-4}$ power law; the correlation with the buoy SWH will go up even if the $\mathrm{HH}$ polarization can only measure the high-frequency part, since both the high- and low-frequency waves now follow the same power law. For VV polarization, the correlation with the wind speed will go up because the power law at the lower frequencies gives information about the wind speed; the correlation with the buoy SWH will stay high, since most of the energy is contained in the lower frequencies, which are readily measured by the wave buoy.

The explanation presented here does not depend directly on wave breaking (although wave dissipation plays a part in forming the $f^{-4}$ power law), and multiple contributing factors are also a possibility.

\section{Conclusion}

In coastal area, the wave fields are inhomogeneous due to the influences of wind, bathymetry and tide, and so forth. Xband marine radar has high spatial and temporal resolutions, so they are suitable to be used in the observation of coastal wave field. To study the differences between $\mathrm{HH}$ and VV polarizations in the observation of coastal waves, the $\mathrm{SWH}$ retrieved from different principal components of radar image sequences are compared with in situ measurements, and the following are found:

(i) The RMSE between the SWH measured by the buoy and those retrieved from different principal components of $\mathrm{X}$-band marine radar image sequences are $0.32-0.45 \mathrm{~m}$ for $\mathrm{VV}$ polarization, and they are $0.37-0.60 \mathrm{~m}$ for $\mathrm{HH}$ polarization. The RMSE are also different under different sea states.

(ii) At the wind speeds of $0-5 \mathrm{~m} / \mathrm{s}$, the RMSE of the $1-5$ th principal component of $\mathrm{VV}$ polarization are smaller than those of $\mathrm{HH}$ polarization, and there are distinct peaks in the wavenumber spectrum of $\mathrm{VV}$ polarization. At very low wind speed $(1-3 \mathrm{~m} / \mathrm{s}$ in the experiment), the backscatter from $\mathrm{HH}$ polarization was too weak to extract information on ocean waves, while the backscatters from VV polarization can be used to estimate the SWH.

(iii) At the wind speeds of $5-18 \mathrm{~m} / \mathrm{s}$, the $\mathrm{SWH}$ retrieved from VV polarized radar images coincide well with the SWH measured by the buoy, while the SWH retrieved from $\mathrm{HH}$ polarization correspond to the variation of the wind speeds. Moreover, the peak spectral wavenumbers of the main principal components of $\mathrm{VV}$ polarization are smaller than those of $\mathrm{HH}$ polarization. So long gravity waves are important to the imaging of $\mathrm{VV}$ polarization, while the windinduced ripples or capillary waves have more important influence on the imaging of $\mathrm{HH}$ polarization. This is different from the composite-surface scattering model for moderate incidence angles [31], so it may be helpful for improving the scattering models under low grazing angles.

(iv) At high wind speeds of $18-26 \mathrm{~m} / \mathrm{s}$, both the SWH measured by the buoy and the wind speeds correspond better with the SWH retrieved from VV polarization than with the SWH retrieved from $\mathrm{HH}$ polarization. The influence of wave breaking on $\mathrm{HH}$ polarization is more important than that on $\mathrm{VV}$ polarization. 
Therefore, the imaging mechanisms of $\mathrm{HH}$ and $\mathrm{VV}$ polarized X-band marine radars are different. In the future, more experiments will be carried out to study the differences between them, especially the non-Bragg scattering mechanisms such as wave breaking. Based on this, the accuracy of the SWH retrieved from X-band marine radar image sequence may be improved.

\section{Competing Interests}

The authors declare that there is no conflict of interests regarding the publication of this paper.

\section{Acknowledgments}

This work was supported by Natural Science Youth Foundation of Jiangsu Province, Grant BK20150905, National Natural Science Youth Foundation of China, Grant 41506199, the Startup Foundation for Introducing Talent of NUIST, 2241061301078, the Fund of Oceanic Telemetry Engineering and Technology Research Center, State Oceanic Administration, under Project no. 2015003, a project funded by the Priority Academic Program Development of Jiangsu Higher Education Institutions (PAPD), and special fund project of the Central Research Institute, numerical prediction of storm surge in typical bays and research on the risk of overflow dam JG1408.

\section{References}

[1] Stennis Space Center, Nondirectional and Directional Wave Data Analysis Procedures, US Department of Commerce, 1996.

[2] B. Lipa, D. Barrick, A. Alonso-Martirena, M. Fernandes, M. I. Ferrer, and B. Nyden, "Brahan project high frequency radar ocean measurements: currents, winds, waves and their interactions," Remote Sensing, vol. 6, no. 12, pp. 12094-12117, 2014.

[3] V. Barale, J. F. R. Gower, and L. Alberotanza, Oceanography from Space, Springer, Berlin, Germany, 2010.

[4] J. D. Paduan and H. C. Graber, "Introduction to high-frequency radar: reality and myth," Oceanography, vol. 10, no. 2, pp. 36-39, 1997.

[5] J. C. Nieto-Borge, K. Hessner, P. Jarabo-Amores, and D. de la Mata-Moya, "Signal-to-noise ratio analysis to estimate ocean wave heights from X-band marine radar image time series," IET Radar, Sonar and Navigation, vol. 2, no. 1, pp. 35-41, 2008.

[6] I. R. Young, W. Rosenthal, and F. Ziemer, "A three-dimensional analysis of marine radar images for the determination of ocean wave directionality and surface currents," Journal of Geophysical Research, vol. 90, no. 1, pp. 1049-1059, 1985.

[7] R. Gangeskar, "Ocean current estimated from X-band radar sea surface images," IEEE Transactions on Geoscience and Remote Sensing, vol. 40, no. 4, pp. 783-792, 2002.

[8] C. M. Senet, J. Seemann, S. Flampouris, and F. Ziemer, "Determination of bathymetric and current maps by the method DiSC based on the analysis of nautical X-band radar image sequences of the sea surface (November 2007)," IEEE Transactions on Geoscience and Remote Sensing, vol. 46, no. 8, pp. 2267-2279, 2008.

[9] H. Dankert and J. Horstmann, "A marine radar wind sensor," Journal of Atmospheric and Oceanic Technology, vol. 24, no. 9, pp. 1629-1642, 2007.
[10] B. Lund, H. C. Graber, and R. Romeiser, "Wind retrieval from shipborne nautical X-band radar data," IEEE Transactions on Geoscience and Remote Sensing, vol. 50, no. 10, pp. 3800-3811, 2012.

[11] P. S. Bell, "Shallow water bathymetry derived from an analysis of X-band marine radar images of waves," Coastal Engineering, vol. 37, no. 3-4, pp. 513-527, 1999.

[12] G. S. Brown, "Guest editorial: special issue on low-grazingangle backscatter from rough surfaces," IEEE Transactions on Geoscience and Remote Sensing, vol. 46, no. 1, pp. 1-2, 1998.

[13] P. Forget, M. Saillard, and P. Broche, "Observations of the sea surface by coherent L band radar at low grazing angles in a nearshore environment," Journal of Geophysical Research: Oceans, vol. 111, no. 9, Article ID C09015, 2006.

[14] P. A. Hwang, M. A. Sletten, and J. V. Toporkov, "Analysis of radar sea return for breaking wave investigation," Journal of Geophysical Research: Oceans, vol. 113, no. 2, Article ID C02003, pp. 1-16, 2008.

[15] P. H. Y. Lee, J. D. Barter, K. L. Beach et al., "X band microwave backscattering from ocean waves," Journal of Geophysical Research, vol. 100, no. 2, pp. 2591-2611, 1995.

[16] D. B. Trizna and D. J. Carlson, "Studies of dual polarized low grazing angle radar sea scatter in nearshore regions," IEEE Transactions on Geoscience and Remote Sensing, vol. 34, no. 3, pp. 747-757, 1996.

[17] L. Cui, Y. He, H. Shen, and H. Lü, "Measurements of ocean wave and current field using dual polarized X-band radar," Chinese Journal of Oceanology and Limnology, vol. 28, no. 5, pp. 10211028, 2010.

[18] J. An, W. Huang, and E. W. Gill, "A self-adaptive wavelet-based algorithm for wave measurement using nautical radar," IEEE Transactions on Geoscience and Remote Sensing, vol. 53, no. 1, pp. 567-577, 2015.

[19] Z. Chen, Y. He, B. Zhang, Z. Qiu, and B. Yin, "A new algorithm to retrieve wave parameters from marine X-band radar image sequences," IEEE Transactions on Geoscience and Remote Sensing, vol. 52, no. 7, pp. 4083-4091, 2014.

[20] Z. Chen, Y. He, B. Zhang, Z. Qiu, and B. Yin, "A new method to retrieve significant wave height from X-band marine radar image sequences," International Journal of Remote Sensing, vol. 35, no. 11-12, pp. 4559-4571, 2014.

[21] G. P. Gerbi, S. E. Kastner, and G. Brett, "The role of whitecapping in thickening the ocean surface boundary layer," Journal of Physical Oceanography, vol. 45, no. 8, pp. 2006-2024, 2015.

[22] Z. Wang, “Tides in the Taiwan strait," Taiwan Strait, vol. 4, no. 2, pp. 120-128, 1985.

[23] Z. Chen, Y. He, J. Pan et al., "Observation of tide from X-band marine radar image sequences," in Proceedings of the IEEE International Geoscience and Remote Sensing Symposium, Beijing, China, July 2016.

[24] O. M. Phillips, "Radar returns from the sea surface-bragg scattering and breaking waves," Journal of Physical Oceanography, vol. 18, no. 8, pp. 1065-1074, 1988.

[25] R. H. Stewart, Introduction to Physical Oceanography, Department of Oceanography, Texas A\&M University, College Station, Tex, USA, 2008.

[26] O. M. Phillips, "Spectral and statistical properties of the equilibrium range in wind-generated gravity waves," Journal of Fluid Mechanics, vol. 156, pp. 505-531, 1985.

[27] H. Hatten, J. Seemann, J. Horstmann, and F. Ziemer, "Azimuthal dependence of the radar cross section and the spectral background noise of a nautical radar at grazing incidence," in 
Proceedings of the IEEE International Geoscience and Remote Sensing Symposium (IGARSS '98), pp. 2490-2492, July 1998.

[28] J. C. Nieto-Borge, G. N. R. Rodriguez, K. Hessner, and P. I. González, "Inversion of marine radar images for surface wave analysis," Journal of Atmospheric and Oceanic Technology, vol. 21, no. 8, pp. 1291-1300, 2004.

[29] W. J. Pierson and L. Moskowitz, "A proposed spectral form for fully developed wind seas based on the similarity theory of S. A. Kitaigorodskii," Journal of Geophysical Research, vol. 69, no. 24, pp. 5181-5190, 1964.

[30] J. Henrique, G. M. Alves, M. L. Banner, and I. R. Young, "Revisiting the Pierson-Moskowitz asymptotic limits for fully developed wind waves," Journal of Physical Oceanography, vol. 33, pp. 1301-1323, 2003.

[31] G. R. Valenzuela, “Theories for the interaction of electromagnetic and oceanic waves-a review," Boundary-Layer Meteorology, vol. 13, no. 1-4, pp. 61-85, 1978. 


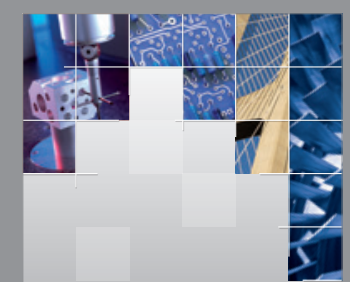

\section{Enfincering}
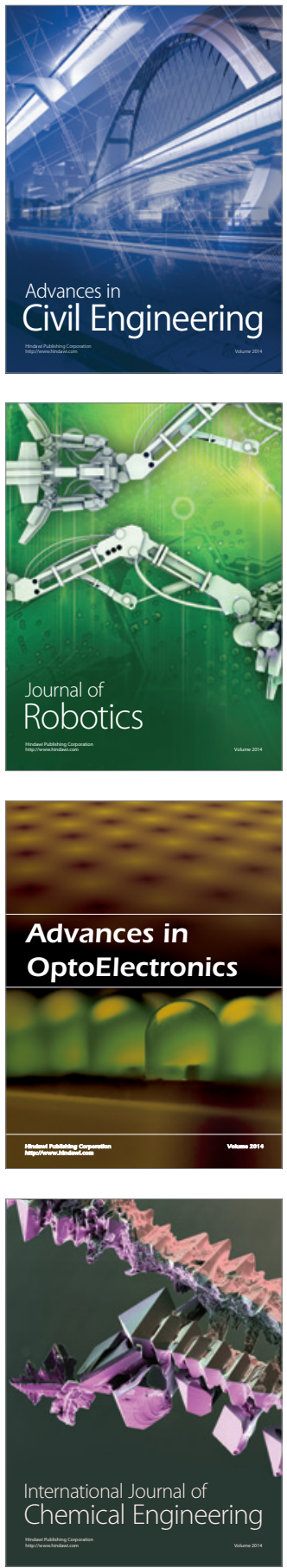

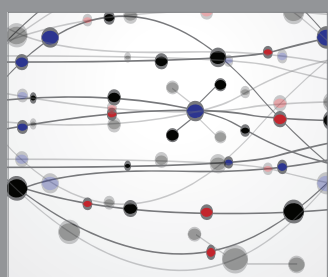

The Scientific World Journal

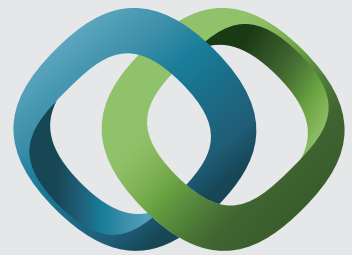

\section{Hindawi}

Submit your manuscripts at

http://www.hindawi.com
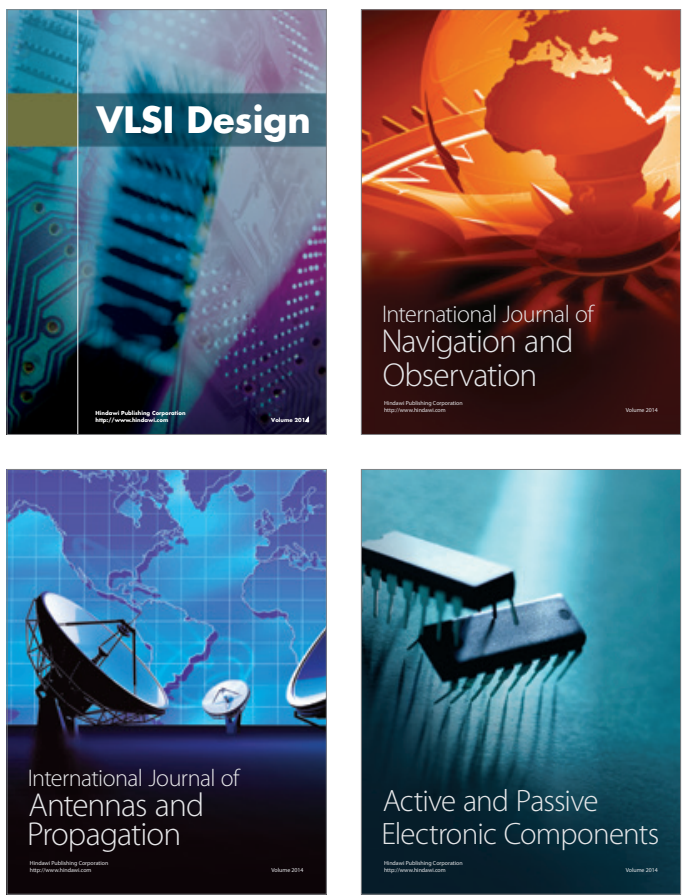
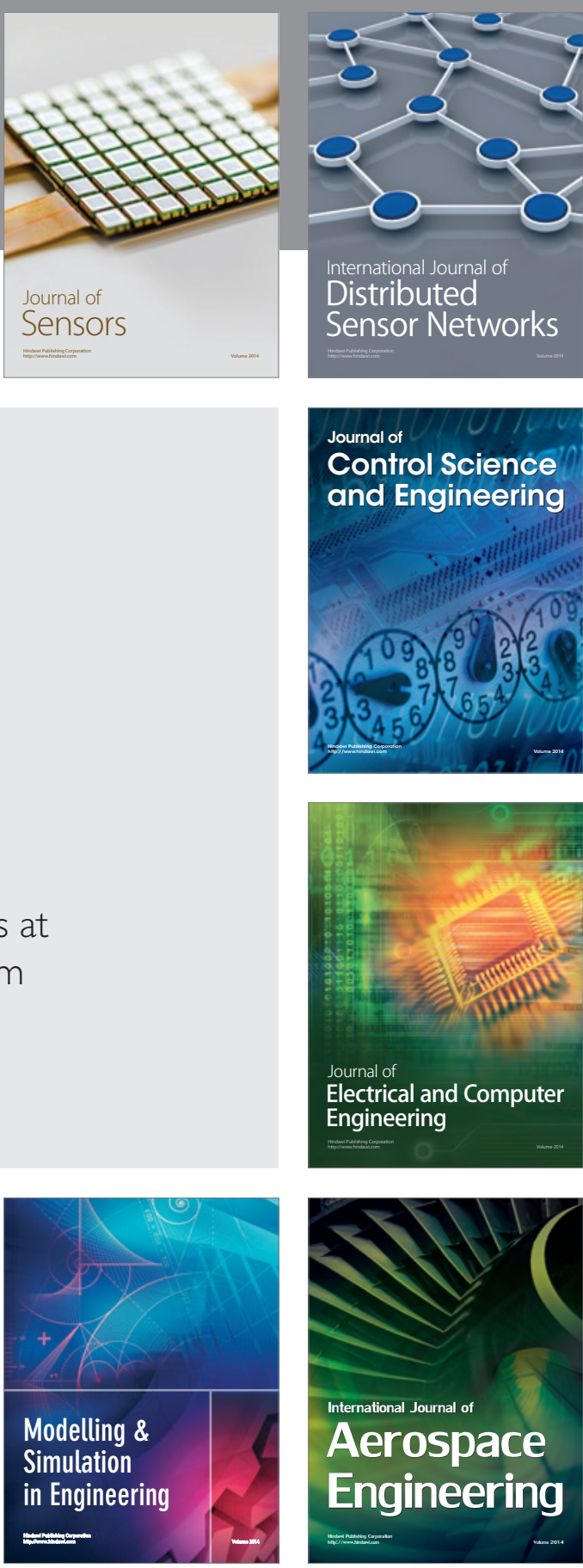

International Journal of

Distributed

Sensor Networks

Journal of

Control Science

and Engineering
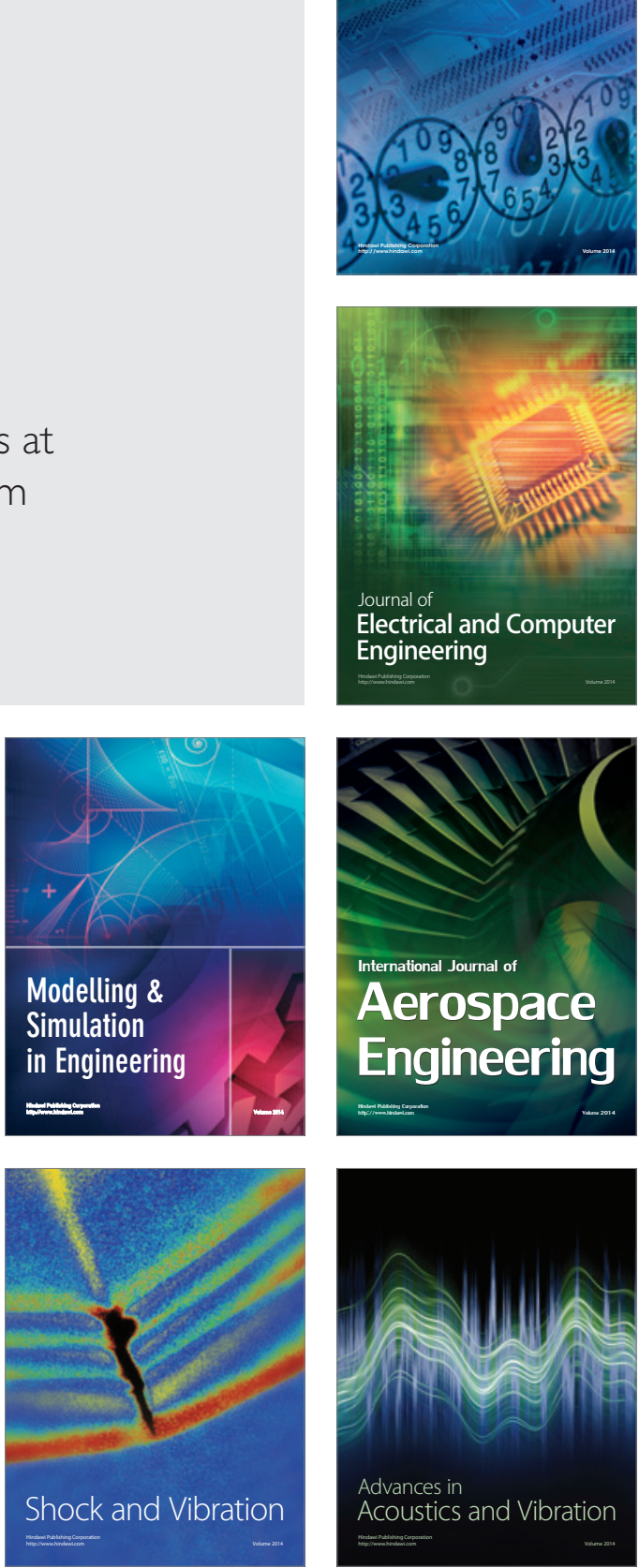